\title{
Inorganic Pyrophosphate Measurement
}

National Cancer Institute

\section{Source}

National Cancer Institute. Inorganic Pyrophosphate Measurement. NCI Thesaurus. Code C161358.

The determination of the amount of inorganic pyrophosphate present in a sample. 